\title{
Research on Salary System Construction of Employees Based on Performance Management
}

\author{
Xinzi Li ${ }^{1, ~ a ~}$ \\ ${ }^{1}$ Xi'an Peihua University, Xi’an, 710125, China
}

Keywords: Performance management, Performance assessment, Salary system construction

\begin{abstract}
Facing the increasingly fierce market competition, enterprises must give full play to the employee's enthusiasm in order to gain competitive advantage. The construction of employee salary system based on performance management is an important method to exert employee's enthusiasm. This paper analyzes the objectives and principles of salary system based on performance management, and gives the design contents of basic salary, performance salary and welfare management to provide some references for the relative researchers.
\end{abstract}

\section{Introduction}

Performance is the sum of employee's work behavior, work result and work attitude in a certain period. Because of the different factors such as time, space, task and working condition, the performance will be different, so the performance shows obvious diversity, multi dimension and dynamic characteristics. In actual work, when performing performance appraisal, we should treat different situations differently and focus more on it. Performance appraisal is based on fact, and it can evaluate the ability, attitude and performance of company members in their daily work, so it is also called performance appraisal. Through the evaluation method to evaluate staff work rigorous, task completion, job performance and employee development by appraisal departments with a goal or standard performance of enterprise work, and give feedback to the management staff the corresponding evaluation results. Salary management, as an important component of human resources development and management, plays an irreplaceable role in arousing employee enthusiasm, excavating staff potential and realizing organization and management strategy. Because of each person's work motivation, needs and personality differences, it is necessary to explore the essence and connotation of compensation management, so that salary management can effectively promote the development and management of human resources. Salary refers to the sum of all forms of labor remuneration that employees receive from organizations where they work. Generally speaking, the salary has broad sense and narrow sense. Generalized compensation includes extrinsic rewards and intrinsic rewards, the external reward refers to the employee and obtain various forms of income from employment, it is divided into: the direct monetary rewards, such as basic salary, allowances, bonuses, stock options; indirect monetary rewards, such as pay insurance, retirement planning, training and company holiday and leave. Internal compensation is the promotion, recognition, or acceptance of work due to hard work. Narrow sense pay mainly refers to the external compensation of enterprises, and from the narrowest point of view, refers to the direct money reward. Enterprise salary management is the process that enterprise managers pay the standard, distribution level, factor structure of enterprise staff salary, assign, adjust and implement.

\section{Objectives and Principles of Salary System Construction Based on Performance Management}

Objectives. The company needs continuous core competence training. This process is difficult, and the company performance management must be able to reflect the process. The process of confirming the performance management index is the process of analyzing and discussing the competitive ability of the company. It is also the process that the managers of the company achieve 
consistency in cognition, and should pay special attention to this link. In addition, the company performance appraisal results should be timely and necessary analysis and feedback, assessment of the company can make a clear understanding of the conclusions of the assessment, to understand their own what gap with excellent company, and then develop the catch-up method. The incentive effect of the wage gap in a reasonable degree, income and responsibility, risk level, contribution, managers and key staff wages increased significantly, the capital, management and other elements distribution of the enterprises, mobilize the enthusiasm of investment managers, members of management personnel, technical personnel, production personnel and other factors the performance; secondly, in the income distribution and reasonable collocation, short-term incentive and long-term incentive, input and output to optimize the allocation of labor costs. Once employees are clear that performance management is helpful and not blame, employees will be more cooperative and frank. Performance management is not a low level of discussion, it is just about employees' job achievement, success and progress, that is, the unanimous desire of employees and managers. The promotion of employee performance is consistent with the benefit of managing the improvement of performance. Therefore, performance management is a management investment that motivates employees to work actively. The key to attracting talent lies in changes in the internal system. The staff of the actual work of the target clear direction to promote performance management, also made clear the corresponding performance will get what kind of reward, so the employees can try to improve their expectations, such as the acquisition of new knowledge and learn new skills to enhance the competence of the work of many, to achieve a certain performance, its greater progress. Therefore, performance management is actually a kind of human capital investment that can help employees to develop.

Principles. Put an end to equalitarianism in the distribution of value, the salary must be tilted to the employees who continuously create value for the company, lean to the key positions of the company, and give reasonable return to the achievements created by the employees. Performance evaluation should be practical and easy to implement. Everything is penalized from actual feasibility. Assessment process can be simplified on the Jane, the examination methods on the "Jane" is not complicated, and less indicators cannot be more. In order to improve the performance appraisal cost budget and control, cost benefit analysis, eliminate all disturbing people, through evaluation activities, harass the people and waste money is not realistic. Performance evaluation standards should be made by combining quantitative and qualitative methods. The principle of fairness and justice should be formulated to ensure that the performance evaluation index system is more scientific and reasonable. Quantitative criteria can be used to formulate relevant standards, and efforts should be made to quantify some qualitative indicators. In order to eliminate or reduce subjective and emotional factors, we must seek truth from facts, not be subjective, nor have the will of the executive. According to the provisions of the evaluation methods, combined with objective assessment data to carry out evaluation, so that the assessed and the required standards to compare, should not be compared between people. According to the provisions of the evaluation methods, combined with objective assessment data to carry out evaluation, so that the assessed and the required standards to compare, and should not be compared between people. Different employees, different abilities, and different contributions may be different. If you receive the same pay regardless of your contribution, it may seem equal, but it is unfair. Must be based on staff capacity and contribution size, reasonably widen the income gap, so that greater contributions to employees to get higher salaries, and actively mobilize the initiative of employees, in order to truly achieve the company's internal equity. Performance appraisal cannot be assessed for assessment, and should be combined with interview process, the performance evaluation results feedback to be examined. Good things persist, carry forward, and rectify and remedy deficiencies. Otherwise, the actual effect of performance appraisal is poor. On the one hand, feedback results, on the other hand, will be given to be explained and explained by the examiner, to encourage staff's achievements and progress, to explain their shortcomings, and identify the direction of future efforts of employees. In the modern human resources management system, continuously improve the level of employee performance concerns become the starting point of performance appraisal, lack of feedback of performance appraisal is of no significance, not only cannot play the staff management function, cannot play the ability to 
develop the function, there is no need for human resource management system as a part of independence. Therefore, the feedback system must be constructed to guide the formation of performance and control the final result of performance.

\section{Design Content of Salary System Construction Based on Performance Management}

Basic Salary. The basic salary is the basic living security for employees. The basic salary of employees is based on the consumption level of the city and the value of each job. According to the post analysis and the post evaluation result, the management salary series is mainly several, etc. the management post salary design mentality is as follows. According to the company's profits in recent years, combined with the external salary survey results, determine the management the first general manager of the post wages; secondly, the design of salary management in other positions is the general manager of the job salary standard, a fixed base layer decreases, the fixed base is determined according to the management all positions of the profit contribution compensation combined with external circumstances; and finally determine the sequence of salary management. Professional and operational job evaluation mainly adopts factor point method, quantitative method to determine the level of post, the design of its post salary is mainly based on the total score of the post evaluation. The design idea is: first of all, determine the general manager position, using the factor points method to calculate the total score. In accordance with the annual salary of the head office and the business objectives and staffing of each unit determined by the head office, the annual salary and wages of each unit shall be determined, and the guiding principle for wage distribution shall be formulated. All units shall pay their salaries within the total amount approved by the head office, and abide by the guiding principles and relevant provisions of the system and the head office on salary distribution. According to the company's business objectives assessment methods, the monthly operation of the company and the company's other units to determine the responsibility target assessment, and according to the assessment results to determine the unit's monthly salary limit. Each unit shall determine the salary distribution of the unit according to the salary distribution quota issued by the company and the guiding principle and provisions of the salary distribution determined by the company.

Performance Salary. Performance pay is measured by the actual value created by employees. It is the most direct form of employee's own hard work. It is the part that can be adjusted by itself and is the most powerful means to motivate employees to work hard. Therefore, the design of performance pay is the key to the design of company performance compensation system. In the actual performance wage determination process, combined with the company's actual project group will pay for performance, customer service, sales claims and accessories business department and market, financial and comprehensive management of logistics departments to be considered separately. After sales, sales, claims and accessories business department is the most direct source of the company's profits, so its performance can be directly quantified indicators of nuclear capacity. Performance indicators mainly include work performance indicators, work attitude indicators, work ability indicators and departmental indicators of four parts, four assessment dimensions are ultimately composite scores. The design of career paths within the enterprise provides a clear career path for employees. It not only let employees know that through their own efforts to reach what position level how much salary, also let employees know that for their ability to have a position in the hierarchy, provides clear guidance for their ability. It can also guide for scientific research personnel service enterprise development strategy, through research and development staff to enhance their own capacity, enhance the competitiveness of enterprises. The financial market, and the comprehensive management of logistics departments not directly to the company to create profits, but they have rich knowledge, skills and strategic management ability, have indirect effect much on the creation of the company's business management and operating profit. Their performance pay design is mainly based on the basic salary and post salary, as well as the annual profits created by the company.

Welfare Management. Employees should be kept in touch with their units during paid annual leave. In case of special circumstances, when the unit needs to recall, it should stop taking leave and 
return to work. For employees whose work needs to be suspended, their remaining holidays should be renewed within this year. Leave at the end of a day in advance shall notify the unit arrangement work; in case of special units cannot be normal holiday, a day early to the unit responsible person that apply for leave procedures according to the relevant provisions. All units and departments do not arrange for annual leave, by the unit leadership and human resources management authority ordered deadline for correction; overdue correction, for subordinate unit's leadership and leadership workshop. After the implementation of paid annual leave, all units should combine the actual work of their own production, without increasing the number of personnel, through technical innovation, improve efficiency and other means to complete the tasks. At the same time, reasonable arrangements for staff work and rest time, and earnestly safeguard the staff's right to rest and leave. The company needs long service employees, such not only can unite the staff confidence, cultivate the loyalty of employees, but also can reduce the cost of training, thus making reasonable seniority wage is particularly important, seniority allowance can be used as subsidies can also be used as an incentive measures. For other management and professional staff of the company, in addition to working overtime on the statutory holidays, overtime pay is not allowed for the rest of the time, and the overtime pay has been reflected in the basic salary. Companies in accordance with national and municipal social insurance regulations for employees to deal with social insurance. Including: old-age insurance, medical insurance, unemployment insurance, work-related injury insurance, maternity insurance. The work injury and maternity insurance shall be paid by the unit and the individual shall not withhold it. Housing provident fund for employees, employees in accordance with the law to enjoy the national housing accumulation fund policy. The housing accumulation fund system is an important housing social security system stipulated by the state law. It has mutual support and security. Companies and individual employees in accordance with the law to pay housing provident fund deposit, special account storage, owned by employees. Housing provident fund for employees to purchase, construction, rehabilitation, overhaul occupied housing, companies and individuals may not be used for other purposes.

\section{Conclusion}

Salary is the main symbol of employee status and success, and it influences employee's attitude and behavior effectively. Salary system construction based on the performance management is to use the human resources management to improve employee's work attitude and ability. In the technology level, it means dealing with the problem of efficiency; in the economic level, it should solve the problem of effectively. The construction of staff salary system based on performance management needs to be improved continuously in practice.

\section{References}

[1] Han Song, Yin Xiaofeng, Wang Fusen, Xie Ming. A Study on Salary and Performance Management System Based on the Concept of "Relative Competitiveness" [J]. Human Resources Development of China, 2015(4): 64-98.

[2] Li Peng, Liu Lixian, Li Yue. The Review of the Influence of Performance-oriented Compensation System on Employee Creativity from the Perspective of Self-determination Theory [J].Science and Technology Management Research, 2015(2): 145-151.

[3] He Xizhen, Li Li. The Practical Research on Hospital Performance Appraisal and Salary Management System [J]. China Health Standard Management, 2017(3): 10-12.

[4] Xie Jianbin. An Empirical Research The Influence of Fairness for Performance Salary on Employee Pay-Satisfaction [J]. Industrial Engineering and Management, 2014, 19(2): 35-39+46. 